\title{
Opportunism and Governance Study on PPP Projects from the Perspective of Contract Theories
}

\author{
Lei Bi \\ International Business Faculty \\ Beijing Normal University \\ Zhuhai, China \\ 185128602@qq.com
}

\author{
Xiaoyu Ma* \\ School of Foreign Languages and International Trade \\ Wenzhou Business College \\ Wenzhou, China \\ sandyxiaoyu@163.com
}

\begin{abstract}
How to improve the performance of PPP projects is a common problem that governments of many countries in the world are bothered by. In China, the theoretical research on the PPP projects is still at the initial stage, only focusing on project management. The western theories on PPP governance are not completely applicable to the PPP projects in China. The innovation of this article is to extend the research perspective from the management level to the governance level, with PPP projects in China as research objects. Series of contract theories, such as incompleteness of contract, residual control rights and so on, are used to analyze the relationship between the government and the private sector and the opportunism involved. Equity governance is considered to be effective in counteracting opportunistic behavior in PPP projects in China.
\end{abstract}

Keywords-PPP projects; Contractual incompleteness; Opportunism; Equity governance

\section{INTRODUCTION}

With rapid development of economy in China, more and better public infrastructure is needed urgently. For better delivering facilities and services to the public, an innovative mode, Public Private Partnership (PPP), is adopted widely. PPP has been used globally in more than 85 countries, which is regarded as a procurement method of construct and operate public infrastructure. The history of PPP can be traced back to decades of years ago. In 1992 the United Kingdom was the first country adopting PPP mode to attract private sector to participate in the provision of public services. In recent years PPP has been applied to such areas as the transportation sector, hospitals, schools and so on in the United Kingdom. In China, the PPP mode has been used at a large scale since the 1990's, especially for water, power and road projects. China has gained lots of valuable experience in implementing PPP projects from many successful cases, such as Line 4 of Beijing Metro, the Beijing National Stadium, the Olympic Water Park Project, the Hangzhou Bay Bridge, the first sewage treatment plant of Shanghai Zhuyuan, etc. With people's better understanding of PPP, PPP mode is believed to be an effective way to ease government's financial burden. Meanwhile, the profits from PPP projects are particularly attractive to the private sector. The "win-win" result is the initial motivator of applying PPP mode to infrastructure projects. PPP mode is regarded as expertise, flexible and cost-awareness management mechanism.

Four principal tasks are generally involved in the process

Sponsor: 2016 Guangdong Planning Project of Philosophy and Social Science [GD16XYJ01]; 2015 Wenzhou Public Welfare Science and Technology Plan Project 2015 [R20150013]; Zhejiang Higher Education Classroom Teaching Reform Project 2016 [kg20160543] of proceeding a project to deliver goods and services to the public.

Task 1: defining and designing the project,

Task 2: financing the capital costs of the project,

Task 3: building the physical assets (e.g. road, school, etc.) for the project, and

Task 4: operating and maintaining the assets for creating goods and services.

During the process of implementing these four tasks, government may intervene by different means. The two ends of the spectrum are a complete private market - private sector performs task 1 to 4 and a pure public enterprise - the government controls task 1 to 4 itself, with no private sector involvement. PPP lies somewhere between a complete private market and a pure public enterprise in the spectrum. PPP helps to reduce costs because of ex ante competition of private sector in the bidding process. Ex ante competition can force bidders to lower costs, raise quality and be innovative. PPP helps to optimize risk allocation with the shifting of risks from the government to the private sector. When the risks are not purely exogenous, bearing these risks gives private sector a strong incentive to control them through careful and high quality operation of projects. In addition to reducing costs and optimizing risk allocation, economy of scale is also one of distinguished advantages of PPP mode, which can get unit costs down to the minimum.

Although possessing numerous advantages, PPP mode is not without its critics. The criticisms mainly concentrate on lack of transparency and the potentially serious problems that may arise when contracts are not well-designed. So while PPP is adopted widely, how to further improve the effectiveness and efficiency of PPP projects should be considered carefully. Framework of contract theories is accepted by scholars as a very effective analysis tool for studying governance mechanism of PPP projects. We argue that contract theories are extremely helpful in understanding the potential costs and benefits of public-private relations and can provide valid guidance for adjusting the governance structure of PPP projects. For better understanding and governing PPP projects, this article explores the relations and behaviors of public and private sectors from the perspective of contract theories. 6 main parts are included in this article: Part I is introduction, Part IIdoes literature review, Part III presents methodology 
and model assumptions, Part IV analyzes instability of contractual relationship and opportunism in PPP projects, Part $\mathrm{V}$ gives the suggestion on contractual governance in PPP projects and Part VI summarizes contributions, limitations and future research.

\section{LITERATURE REVIEW}

\section{A. Contract Incompleteness}

Coase (1937) realized the incompleteness of contract. Coase pointed out that owing to the difficulty of forecasting, the longer the period of the contract is for the supply of the commodity or service, the less possible, and indeed, the less desirable it is for the person purchasing to specify what the other contracting party is expected to do [1]. Williamson (1985), Klein (1978) considered that the contract is incomplete with the bounded rationality of agents [2][3]. Stiglitz (1999) and Schwartz (1999) pointed out that perfect rationality should be replaced by bounded rationality, symmetry of information should be replaced by dissymmetry of information and zero transaction costs should be replaced by positive transaction costs. Modern contract theories firstly distinguish complete contract and incomplete contract.

Incomplete contract theories hold that agents concerned and the third party cannot confirm or observe everything due to individual's bounded rationality, information dissymmetry and positive transaction costs. As the result, the terms of contract are incomplete. Tirole (1999) attributed the incompleteness of contract to three factors: (1) the agents' rationality is bounded so as not to foresee all future contingencies; (2) even the agents can foresee all future contingencies, but the cost of writing all of them in the contract is high; (3) some information can be observed by agents, but it cannot be verified by the third party, such as court[4].

The contract, the information of which is neither observable nor verifiable, is called unavoidable incomplete contract by the economic theorists. There are two key factors leading to "unavoidable incomplete contract": information incompleteness and specific investment. PPP contract is regarded as unavoidable incomplete contract.

Hart (1999) attributed the cause of contract incompleteness to the indescriptability of key variables and the unverifiability of the third party [5].

Maskin \& Tirole (1999) argued that the basic purpose of contracting is not to describe physical contingencies but to specify pay off contingencies. That is, the nature of contract should be pay off dominated. The incompleteness of the contract is irrelevant to the indescriptability of the natural state or the unverifiability of the third party. This is called the MT irrelevance theorem[6]. Kunimoto (2008) developed the MT irrelevance theorem. If the information is asymmetric in both signing phase and transaction phase, the unpredictable contingency is crucial to the incompleteness of contract. However, if the information is symmetrical in signing phase, the unpredictable contingency is inconsequential even if the information in transaction phase is asymmetric [7].
Research in recent years focuses on the intrinsic factors of contract incompleteness. One type of research insists on the hypotheses of complete rationality, and argues from different perspectives that the incompleteness of contract is the result of rational selection of participants. Many studies have shown that when the environment tends to be complex or the costs of contracting and executing are too high, the optimal contract may be simple contract or gentlemen's agreement.

\section{B. Contractual Relationship and Governance in PPP Projects}

Savas (2002) proposed that private sector should be involved in the provision of public products and services, and meanwhile for ensuring private sectors' legitimate rights and interests prior agreement should be made with public sector through contracting. Arping (2002) pointed out that the essential of PPP mode is to design a series of contracts for eliminating investment risks caused by asymmetry information, decreasing transaction costs, improving mechanism of risk management, and forming an effective incentive mechanism [8]. Spackman (2002) analyzed the UK infrastructure PPP projects and believed that private sector has the same status with the public sector and plays a more important role. Grimisey \& Lewis (2002) pointed out that neither participant in the PPP mode achieves the maximization of their own interests, but the total revenue reaches the maximum, which is more in line with the purpose of the PPP projects. Grout (2005) believed that there is inherent similarity between the PPP mode and the outsourcing mode. An (2014) provided an in-depth analysis of how to solve the cooperative surplus problem generated by contingent events.

For analyzing risk management of PPP contract, Cheung \& Chan (2011) adopts literature review methodology, and Li \& Zou (2011) adopts AHP-based risk assessment methodology. Ogu (2000) believed that PPP contract needs to clearly stipulate the responsibilities, obligations and risks undertaken by both government and private sector for better protecting the interests of both parties. Doh \& Ramumurt (2003) identified PPP risks mainly from the perspective of the government, and believed that the government must act as both an initiator and a consumer of PPP projects, and must also act as a rule maker. Ewijk \& Tang (2010) proposed to apply camp model for risk assessment of PPP projects. Risk identification, risk assessment and risk sharing are all components of this model. Qi \& Ke (2009) summarized the failed or troublesome PPP projects in China, analyzed in depth the reasons of risks, and proposed the suggestions on how to manage risks. He (2011) constructed an optimal cooperative game model for the government and private sector, determining the optimal risk sharing ratio between the two parties. Zhou \& Chen (2014) believed that the franchise contract should be designed to reshare ex post risks.

In general, the current literature on PPP mode mainly focuses on its application and risk control. Contract governance is a comparatively new studying direction. Contract, as a constraint and incentive mechanism, is also thought of as an effective governance tool of PPP projects. Guash \& Straub (2006) sustained that PPP participants are linked together through contracts, in which way government's administrative burden can be released and public services 
efficiency can be improved. Meanwhile, they suggested that appropriate contract governance mechanism should be chosen for dealing with interest conflict of different PPP participants [9]. Li (2010) proposed such basic types of contract for governing PPP projects in the specific environment of China as administrative contract, civil contract and social contract. Yan \& Zhao (2005) analyzed the similarities and differences among PPP project contract, enterprise contract and market contract, and further analyzed the contract governance mechanism of PPP projects. Shi \& Yang (2011) proposed flexible incentive mechanism for governing PPP projects based on project governance theory and incentive theory. Engel et al. (2008) studied the characteristics of the optimal contract and identified the usual contracting format in road building.

The modern contract theories hold the idea that the main parties involved in business activities are connected by series of contracts. The nature of PPP projects is the combination of contracts concluded by all the participants. Among various contractual relations in PPP projects, the contractual relationship between the government and private sector occupies the core position, which is the basis for the establishment and maintenance of other contractual relations. Due to the inconsistent objectives and the asymmetric information between the government and the private sector, many problems unavoidably arise in the process of operating PPP projects. It can be seen that the existing literature mainly focuses on the application and risk management of PPP mode, but lacks the research on problem-oriented contractual governance. Therefore, based on the existing research, this article analyzes he main problems existing in PPP projects and puts forward the ideas of contractual governance.

\section{Methodology And Model Assumptions}

\section{A. Methodology}

Contract theories have been certified to be effective for studying the relationship between the government and private sector and exploring governance mechanism in PPP projects.

In this article, contract theories are applied to discuss possible opportunism between the government and the private sector in PPP projects of China. Furthermore, an equity allocation model is constructed to give suggestions on how to govern public-private relationship through equity contract in PPP projects.

\section{B. Model Assumption}

Assumptions are proposed as follows:

H1 In PPP projects, both main contractors - the government and the private sector - possess bounded rationality and limited information.

H2 Contractors' long-term contractual relationship is unstable. If effective governance mechanism is not engaged, unavoidable opportunistic behaviors between them will definitely happen.

H3 Sound equity allocation between the government and the private sector will effectively counteract opportunism.

\section{INSTABILITY OF CONTRACTUAL RELATIONSHIP AND OPPORTUNISM IN PPP PROJECTS}

\section{A. Instability of Public-private Contractual Relationship}

In PPP projects, the contracts between the government and the private sectors are incomplete. Owing to bounded rationality and limited information, it is impossible for contractors to plan for every potential contingency. And even if every contingency could be predicted, it would probably be difficult to write down these plans in a contract that is enforceable by law.

The duration of most PPP contracts is comparatively long, which helps to motivate cooperative game between the government and the private sector. Longer contract duration plays a role in reducing opportunistic problems in franchise system[10]. Generally speaking, long-term contract helps to motivate cooperation between the government and the private sector, but the cooperative solution is not stable. Gibbons (1997) developed an infinitely repeated game model to analyze the stability of contractual relationship, and $\mathrm{Wu}$ Desheng (2008) modified the model which is adopted to discuss the instability of contractual relationship between the government and the private sector.

\section{Situation 1: If certainty exists}

Suppose that B (the private sector) can get payoffs $\mathrm{C}$ if they choose to cooperate with $\mathrm{A}$ (the government) and get payoffs D otherwise. B can get payoffs $P$ from their special investment when the contractual relationship with $\mathrm{A}$ is interrupted. $\mathrm{D}>\mathrm{C}>\mathrm{P}$. When certainty exists, the private sector can get payoffs stream $(\mathrm{C}, \mathrm{C}, \mathrm{C} \ldots \ldots)$ from cooperation, and get payoffs $(\mathrm{D}, \mathrm{P}, \mathrm{P} \ldots \ldots$ ) from violation of contract. $\gamma$ represents a discount rate. The private sector chooses to cooperate only when payoffs from cooperation exceed payoffs from violation, namely

$$
\mathrm{C}+\frac{\mathrm{C}}{\gamma}>\mathrm{D}+\frac{\mathrm{P}}{\gamma}
$$

Solving (1), shows

$$
0<\gamma<\frac{\mathrm{C}-\mathrm{P}}{\mathrm{D}-\mathrm{C}}=\gamma^{*}
$$

According to (2), when $\gamma<\gamma^{*}$, the contractual relationship between the government and the private sector is stable. With the decreasing of $\gamma$, the private sector pays more attention to future payoffs and then cooperation rather than violation is preferred. Cooperation brings about payoffs $\mathrm{C}-\mathrm{P}$ each period, and violation brings about current payoffs $\mathrm{D}-\mathrm{C}$ and payoffs of $P$ in each of following periods.

\section{Situation 2: If uncertainty exists}

In accordance with above analysis, when uncertainty exists, the private sectors can get payoffs stream $\left(\mathrm{C}_{1}, \mathrm{C}_{2}, \mathrm{C}_{3}, \ldots \ldots\right)$ and $\left(D_{1}, P_{2}, P_{3} \ldots\right)$ respectively from cooperation and violation. $\mathrm{E}\left(\mathrm{C}_{\mathrm{t}}\right)=\mathrm{C}, \mathrm{E}\left(\mathrm{P}_{\mathrm{t}}\right)=\mathrm{P}$. For simplicity, we shall assume that the 
private sector is risk neutral and concerns about expected revenue without the consideration of any risks. With suitable normalizations, the condition for cooperation can be rewritten as

$$
\mathrm{C}_{1}+\frac{\mathrm{C}}{\boldsymbol{\gamma}}>\mathrm{D}_{1}+\frac{\mathrm{P}}{\boldsymbol{\gamma}}
$$

Solving (3), showing

$$
\gamma<\frac{\mathrm{C}-\mathrm{P}}{\mathrm{D}_{1}-\mathrm{C}_{1}}=\gamma^{*}
$$

According to (4), whether or not the contractual relationship between the government and the private sector is stable is decided by the extremum of $D_{1}$ and $C_{1}$, namely SupD and $\operatorname{InfC}_{1}$. The condition for cooperation can be rewritten as

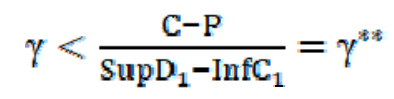

When the probability distribution of $D_{t}$ and $C_{t}$ is ensured, the private sector can get the most payoffs from violation with maximum of $D_{1}$ and minimum of $C_{1}$. If (5) is not satisfied, the private sector' payoffs from violation exceed those from cooperation, and the private sector gets enough motivation to interrupt contractual relationship with the government. Obviously, when the extremum of $\mathrm{D}_{1}$ and $\mathrm{C}_{1}$ is taken, $\gamma^{*}>\gamma^{* * 2}$. This indicates that the private sector has more incentives to violate contracts under the circumstances of uncertainty.

PPP projects generally belong to large-scale projects, the duration of which is comparatively long. And there exist lots of uncertainty factors in PPP projects. Government intervention is a primary uncertainty factor. Government intervention is only appropriate if unless so the general public interest will be substantially affected. Unreasonable government intervention will ruin the interest of private sector and discourage the private sector's confidence on PPP projects It was reported that some PPP projects in China failed because of too much government intervention. Insufficient public credit of government is also the major uncertainty factor. For attracting private sector to participate in PPP projects, the government usually makes promises which are hard to be fulfilled. As a result, the interest of both government and private sector is damaged. Financing risk is another uncertainty factor holding back the implementation of PPP projects. In PPP projects, private sector's requirement of longterm loans is often unsatisfied and the credit policies to the private sector are often restricted. What's more, completion risk is one of uncertainty factors as well, which may cause PPP projects to deviate from the initial schedule.

It is uncertainty that makes contractual relationship between the government and the private sector more unstable, which is also in accordance with Williamson's important conclusion that uncertainty has a negative effect on the stability of contractual relationship.

\section{B. Opportunism in PPP Projects}

In PPP projects, it is contract incompleteness and uncertainty factors that make opportunistic behavior between the government and the private sector unavoidable. Moral hazard and hold-up problems are two main forms of opportunism.

As there exists such a fact in corporate world that one party's effort level may not be fully observable, and consequently moral hazard problem arises. In principal-agent theory, moral hazard is one-sided problem. The principal is fixed and the agents are variable. For the moral hazard problem, only the agents' action matter. In PPP projects, the government is fixed and regarded as the principal. Meanwhile, the private sector is variable and should do contribution to the PPP's performance. The private sector is regarded as the agents. Such a fact should be aware that the private sector's self-interest is not always in accordance with the interest of the government and sometimes the private sector's effort does not benefit the PPP's performance. As the private sector's efforts can not be fully observable by the government the private sector is the subject of the moral hazard problem in principalagent theory. In PPP projects, comparing with the government private sector is more experienced in identifying the projects' risks and difficulties and more accurately evaluate selfcapability of operating projects. In PPP projects moral hazard problems are classified into two categories: hidden information and hidden behavior. During bidding period the private sector may make use of the loophole in bidding document to do asymmetric pricing, and they may also hide important information for unreasonably claiming for post changes and compensation. What's more, the government in the bidding stage usually chooses the private sector in accordance with the principle of the low price bidding. This may induce the private sector to quote at prices below cost. Afterwards, due to the small profit margin caused by the low bidding price the private sector often takes subcontracting, does shoddy work and uses inferior material to reduce project cost. Eventually the jerry-built projects may appear because of insufficient investment in technology, equipment, and materials.

Hold-up problem is another form of opportunism. It's known that both the government and the private sector need to make asset specific investment for PPP projects. Four specialized forms are usually involved in asset specific investment: specialized physical assets, specialized human assets, specialized site specificity and dedicated assets. All of these four specialized assets can be found in PPP projects. In Klein's opinions, after specialized assets are invested, the behavior of appropriating specialized quasi rents may take place and hold-up problem may come into being. It should be clearly aware that the reasons of hold-up problem are not the same with those of moral hazard. For the moral hazard, it is asymmetric information that leads to opportunistic behavior. Yet for hold-up problem, the information is symmetric to both contractors. It is contractual incompleteness that leads to ex post opportunistic behavior. In PPP project, both the government and the private sector have specific investment, but their investment is asymmetric. The government's main specific investment is capital, and the private sector's main 
specific investment is manpower, equipment and etc. Therefore, for the government and the private sector, there exit differences in the difficulty of transferring specialized assets. Comparing with the government, it is easier for the private sector to transfer specific investment to other projects, which causes the government lose more if public-private relationship breaks up. The government has to spend more cost for choosing a new private sector, including the cost of re-bidding, the additional payment to the new private sector for cleaning and maintaining the mess left by the previous private sector, the cost of employing lawyer to litigate the previous private sector, the extra insurance for the new private sector due to the uncertainty aroused by the previous private sector. In addition, hold-up problem may exist because of the private sector's advantage of asset specificity. For example, when the project is in the halfway of process, the private sector proposes to make changes to the design and charges high prices for the changed parts.

\section{CONTRACTUAL GOVERNANCE IN PPP PROJECTS}

What kinds of contracts may create incentives for reducing the common problems in franchise system? Fixed revenue contract is not the optimal way of dealing with the problems of opportunism in PPP projects. On the contrary, fixed revenue contract might motivate the private sector to shirk because the revenue is the same regardless of work quality and levels of efforts.

When private sector has the tendency towards shirking, fixed revenue contract should be replaced by the contract allowing residual claimancy on the profit of PPP projects. A number of scholars point out that the contracts allowing residual claimancy on the profits give the private sector strong motivation of not engaging in opportunistic behavior.

For turning the private sector into residual claimants on the profit of PPP projects, private sector should be owner-operator. Ownership is one of important incentives in PPP projects. If not possessing ownership, the private sector only takes the role of manager. Then the government has to impose more cost of managing the agency relationship. Moreover, if a PPP project is operated by private sector that has not ownership, opportunism is harder to be avoided.

When the government and private sector participate in the PPP projects, they have different interests. The main consideration of the government is smooth operation of projects, the quantity and quality of public goods, and the risks the government may undertake. And the main consideration of private sector is policy stability, business risks, government guarantees and cooperation, and the government integrity.

At present, the application of the PPP mode in China's infrastructure projects is still in the initial stage. There exist the following situations: firstly, comparing with the private sector the government's equity ratio accounts for absolute controlling position. This is still similar to the traditional mode in which the government takes the main responsibility of offering public goods and services. In this situation the private sector bears almost no responsibility; secondly, the private sector occupies larger equity ratio than before, but its equity allocation is relatively dispersed. So the private sector plays limited roles in checking and balancing government's authority. The government is still in dominant position in operating PPP projects, which is not helpful for counteracting opportunism.

In the PPP projects, the contradictions and conflicts between the government and the private sector can be considered to be balanced by adjusting the structure of the equity ownership. Assuming that the return rate, operating risk and cooperation residual created by PPP projects is the common knowledge for both government and private sector, and all contractual items involved can be quantified into cooperation residual $\mathrm{R}$. According to the rotational bidding model, in the first stage, the government firstly bids for the equity ratio $X_{1}$, the cooperation residual obtained by the government is $r_{1}=X_{1} R$, and the cooperation residual for the private sector is $\left(1-X_{1}\right) R=R-r_{1}$. In the first round of bidding, private sector has the options of accepting or rejecting the contractual terms provided by the government. If the private enterprises accept them, the equity ratio between the government and the private enterprises is $\left(X_{1}, 1\right.$ $\left.X_{1}\right)$, and the cooperation residual is $\left(r_{1}, R-r_{1}\right)$. Then the game is over. Otherwise the next round of bidding begins.

Rejecting the contractual terms proposed by the government in the first round, the private sector proposes a revised equity ratio $\left(1-X_{2}\right)$ in the second round. Then the equity ratio of the government is $X_{2}$, and the government's cooperation residual is $r_{2}=X_{2} R$. The private sector's cooperation residual is $\left(1-X_{2}\right) R=R-r_{2}$. In the second round of bidding, the government may choose to accept or reject private sector's proposal. Suppose that the discount factor is $\delta \quad(0<\delta<1)$. If the government accepts private sector's proposal, the equity ratio between the government and private enterprises is $\left(X_{2}, 1-X_{2}\right)$, and the cooperation residual is $\left(\delta X_{2} R, \delta R\left(1-X_{2}\right)\right.$ ). Then the game is over. Otherwise, the next round of bidding begins.

In the third stage, the government and private sector put forward a compromise on the equity ratio and other contractual terms. In this stage, the government and the private sector have to consider the game results of the previous two stages. Both parties can not unilaterally allow themselves to have a larger equity ratio and obtain more cooperation residual. Each other's expected cooperation residual should be considered by both the government and the private sector. Therefore, in the third stage, the equity ratio proposed by the government is $X$, and the government's cooperation residual is $r=x R$. Accordingly the equity ratio of private sector is 1$X$, and the private sector's cooperation residual is 
$(1-x) R=R-r$

In this stage, if the private sector accepts the government's proposal, the cooperation residual of the government and the private sector is $\left(\delta^{2} x R, \delta^{2} R(1-x)\right.$ ). If the private sector refuses the government's proposal, the government will choose not to cooperate with the private sector because the equity ratio ${ }^{X}$ is its maximum concession. With the end of the game, the cooperation residual of both parties is zero.

By the backward induction, it can be seen that in the third stage of the game the best game strategy for the private sector is to accept the government's proposal with $0<1-x<1$, $0<\delta<1, R-r>0$. Though knowing in advance that the private sector's best strategy is to accept the proposal, the government shouldn't require too large equity ratio $X$. Large equity ratio $X$ ensures that the government obtains large proportion of cooperation residual, but it makes private sector's proportion of cooperation residual $R-x R$ too small. Under these circumstances, private sector would rather reject the government's proposal than accept it.

In the second stage, the private sector knows that the government puts forward equity ratio ${ }^{X}$ for itself, and then the government and the private sector obtain cooperation residual ( $\delta^{2} x R, \delta^{2} R(1-x)$ ). In order to reduce the bargaining cost and prevent the negotiation from entering the third round, the rational private sector proposes equity ratio

$X_{2}$ in the second stage. The equity ratio $X_{2}$ should allow the government's cooperation residual in the second stage not less than that in the third stage. Meanwhile the equity ratio

$X_{2}$ should also make the private sector obtain more cooperation residual in the second stage than that in the third

stage. Therefore, in the second stage the equity ratio $X_{2}$ proposed by the private sector should satisfy

$$
{ }_{6} \delta X_{2} R \geq \delta^{2} x R \text {, that is, } X_{2} \geq \delta x
$$

Put (6) into $\delta R\left(1-X_{2}\right)$, and the private sector remains cooperation residual

$$
\delta R(1-\delta x)
$$

Making comparison between (7) and the private sector's cooperation residual $\delta^{2} R(1-x)$ obtained in the third stage, we can see that private sector's cooperation residual in the second stage is more than that in the third stage with $0<\delta<1, \delta R(1-\delta x)>\delta^{2} R(1-x)$.
In addition, the government understands that it can get equity ratio $x$ and cooperation residual $\delta^{2} x R$ in the third stage and that it can get equity ratio not less than $\delta x$ and cooperation residual $\delta^{2} x R$ in the second stage. The government also understands that in the second stage the private sector satisfies its own needs and interest with the cooperation residual $\delta R(1-\delta x)$. In order to reduce the bargaining cost, the rational government proposes appropriate equity ratio to the private sector in the first stage, satisfying both private sector's requirement to cooperation residual $\delta R(1-\delta x)$ and its own requirement to cooperation residual not less than $\delta^{2} x R$. To achieve this, let

$$
\begin{aligned}
& r_{1}=R-\delta R(1-\delta x), \text { that is, } \\
& \qquad r_{1}=R-\delta R+\delta^{2} \times R
\end{aligned}
$$

From (8), it can be seen that $r_{1}>\delta^{2} x R$ with $R-\delta R>0$. That is to say that the cooperation residual obtained by the government is more than that $\delta^{2} x R$ in the second and the third stage of game.

Therefore, from the above analysis of game equilibrium, it can be seen that the only subgame perfect Nash equilibrium solution for the cooperative game between the government and private sector is $\left(R-\delta R+\delta^{2} x R, \delta R-\delta^{2} x R\right)$. The private sector's cooperation residual is

$$
\delta R-\delta^{2} x R=\delta R(1-\delta x)
$$

From (9), it can be seen that the private sector's cooperation residual is determined by the discount factor $\delta$ and the government's equity ratio $x$. The discount factor reflects the bargaining cost between the government and the private sector. The private sector's cooperation residual is zero if the discount factor $\delta$ is zero. When $\delta$ equals to $\frac{1}{2 x}$, the private sector's cooperation residual reaches the maximum $\frac{R}{4 x}$. Therefore, when negotiating with the government the rational private sector should reasonably shorten the negotiation process and reduce the negotiation costs.

The equity ratio plays a crucial role in the final distribution of cooperation residual between the government and the 
private sector. In order to encourage the private sector to actively participate in PPP projects, the government should give the private sector a larger equity ratio. This also means that the equity governance is the core content of the contract governance between the government and the private sector.

In China, series of policy have been developed to encourage social capital to participate in the infrastructure projects and it is accepted that the private sector plays a more important role in PPP projects. The government should moderately distribute larger equity ratio to the private sector for inspiring private sector's enthusiasm and improving management efficiency of PPP projects. Meanwhile the power between the government and the private sector can be balanced and the opportunistic behavior of both parities can be counteracted, which helps to PPP projects running smoothly.

\section{CONTRIBUTIONS, LIMITATIONS AND FUTURE RESEARCH}

How to improve the performance of PPP projects is a common problem that countries in the world are bothered by. Resolving this issue depends on neither returning to administrative control of government nor complete market competition, but adopting appropriate way of governance. In western countries, the research on PPP projects has developed from the project management level to the project governance level and from the initial discussion on concepts and functions to in-depth study on transaction method, governance mechanism and so on. However in China, the theoretical research on the PPP projects is still at the initial stage, and only focuses on project management. Due to the different implementation environment, the western theories on PPP governance are not completely applicable to the PPP projects in China. This article takes PPP projects in China as the research object, and extends the research perspective from the management level to the governance level, with the expectation of making certain contribution to the theoretical innovation. In addition, this article analyzes PPP-related problems from the perspective of contract which is considered as an effective analysis perspective of project governance. The contract theories, such as the incompleteness of contract, residual control rights and so on, are very helpful for correctly understanding the relationship between the government and the private sector and for designing the appropriate governing structure for PPP projects.

Western research on the governance of PPP projects began to consider the influence of social factors, and more and more research emphasizes relational governance. Relational governance has been accepted as important governing mechanism by academia. Although there are some common basic elements in relational governance, some unique elements in different cultural background should also be accounted for governing PPP projects. Based on equity governance, the future research will explore the elements of relational governance suitable for Chinese cultural background, and explore the relationship between relational governance and explicit contract governance, putting forward more effective suggestions for PPP project governance.

\section{REFERENCES}

[1] R. H. Coase, "The nature of the firm, " London: Economica, vol. 16, pp. 386-405, 1937.

[2] O.E. Williamson, "Assessing contract," Oxford: Journal of Law, Economics,\& Organizations, vol. 1, pp. 177-208, 1985.

[3] B. Klein, R. Grawford, and A. Alchian, "Vertical integration, appropriable rents, and the competitive contracting process," Chicago: Journal of Law and Economics, vol. 21, pp. 297-326, 1978.

[4] J. Tirole, "Incomplete contract: where do we stand?" Chicago: Econometrica, vol. 67, pp. 741-781,1999.

[5] O. Hart and J. Moore, "Foundations of incomplete contracts," Oxford: The Review of Economic Studies, vol. 66, pp. 115-138, 1999.

[6] E. Maskin and J. Tirole, "Unforeseen contingencies and incomplete contracts," Oxford: The Review of Economic Studies, vol. 66, pp. 83114, 1999.

[7] T. Kunimoto, "Indescribability and asymmetric information at the contracting stage," New York: Economics Letters, vol. 99, pp. 367-370, 2008 .

[8] S. Arping, "The role of convertibles in syndicated venture fiancing," Indiana: Journal of Business Venturing, vol. 2, pp. 139-154, 2002.

[9] J.L. Guasch and S. Straub, "Fuzzy AHP-based risk assessment methodology for PPP projects," Virginia: Journal of Construction Engineering and Management, vol. 12, pp. 1205-1209, 2011.

[10] I. Ruuska, T. Ahola, and K.A. Artto, "New governance approach for multi-firm projects: lessons from olkiluoto 3 and flamanville 3 nuclear power plant projects," Vienna: International Journal of Project Management, vol. 29, pp. 647-660, 2011. 